\title{
Non-Native Insects in Urban and Forest Areas of Slovenia and the Introduction of Torymus sinensis with Dryocosmus kuriphilus
}

\author{
Maja Jurc ${ }^{*}$, Srdjan Bojovic ${ }^{2}$, Dušan Jurc ${ }^{1,3}$ \\ ${ }^{1}$ Biotechnical Faculty, Department for Forestry and Renewable Forest Resources, University of Ljubljana, Ljubljana, Slovenia \\ ${ }^{2}$ Department of Ecology, Institute for Biological Research “Siniša Stanković”, University of Belgrade, Belgrade, Serbia \\ ${ }^{3}$ Department for Forest Protection, Slovenian Forestry Institute, Ljubljana, Slovenia \\ Email: *maja.jurc@bf.uni-lj.si
}

How to cite this paper: Jurc, M., Bojovic, S., \& Jurc, D. (2017). Non-Native Insects in Urban and Forest Areas of Slovenia and the Introduction of Torymus sinensis with Dryocosmus kuriphilus. Open Journal of Forestry, 7, 416-427. https://doi.org/10.4236/ojf.2017.74025

Received: July 11, 2017

Accepted: October 14, 2017

Published: October 17, 2017

Copyright $\odot 2017$ by authors and Scientific Research Publishing Inc. This work is licensed under the Creative Commons Attribution International License (CC BY 4.0).

http://creativecommons.org/licenses/by/4.0/

\section{(c) (†) Open Access}

\begin{abstract}
We survey non-native insects species in whole territory of Slovenia. Data on non-native species were collected in field, and we also used results of projects in which we participated and with overview of literature data in scientific publications. Correspondence Analysis (CA) of data was carried out with the software Statgraphics Centaurion XVI, U.S.A. Up to 254 non-native insect species are present: around $83 \%$ are phytophagous ( $43 \%$ feed on woody plants, $40 \%$ on other plants); around $12 \%$ are non-phytophagous; and $5 \%$ are parasitoids or predators of other insects or mammals. Among the phytophagous species, Hemiptera predominates (with $38.2 \%$ ), followed by Coleoptera $(29.8 \%)$ and Lepidoptera (14.5\%). Non-native insects that do not feed on plants include Coleoptera (80\%), Lepidoptera (6.5\%), Hymenoptera (6.5\%) and Diptera (6.5\%). Most of phytophagous species are associated with introduction of plants on which they are specialists, but some have also shifted from introduced to native plant hosts. 36 non-native phytophagous species (14.17\% of all non-native insects) have become harmful plant pests of urban trees and crops. 20 appear on woody plants, but only Dryocosmus kuriphilus, appears in urban forest areas. In the past decades species such as $D$. $\mathrm{ku}$ riphilus, Leptoglossus occidentalis, Xylosandrus germanus, Gnathotrichus materiarius, Dasineura gledichiae, Phyllonorycter issikii, Cinara curvipes, Ophiomyia kwansonis have been recorded in parks and forests. Some non-native species are spreading in Slovenian urban forests and affect economic, ecological and other forest and urban forest functions. The number of harmful insects in forests is extremely small probably due to high diversity of the forest ecosystem, where close-to-nature forest management is practiced,
\end{abstract}


which retains forest's self-regulatory ability to control pests. Such management enables for example the reduction of D. kuriphilus with expansion of its parasitoid, Torymus sinensis. We attempt to explain this phenomenon: we assume that $T$. sinensis was introduced in Slovenia as diapaused eggs in its host, D. kuriphilus.

\section{Keywords}

Urban Forest Areas, Forests, Non-Native Insects, Non-Native Parasitoids, Dryocosmus kuriphilus, Torymus sinensis

\section{Introduction}

\subsection{Species Biodiversity of Slovenia and Ecosystem Health}

Slovenia is known for very high species diversity. Ecological conditions are extremely diverse due to the intertwining of different climatic, tectonic, edaphic, orographic, lithologic and other elements; consequently, it is considered a transitional or ecotonic region. Slovenia is the habitat of more than 15,000 animal species, 6000 plant species and 5000 fungi species. With a forest cover of $58.4 \%$ $(1,184,526 \mathrm{ha})$ it is among the most forested European countries. In only $4.9 \%$ of national territory, the distance from one forest to the nearest forest exceeds 500 $\mathrm{m}$ (Hočevar, 2003). Analysis covering the period from 1875 shows that the forest area is constantly increasing. Forest vegetation structure is highly diverse. Most forests are located within beech (44\%), fir-beech (15\%), thermophile deciduous trees and pines (12\%), and beech-oak (11\%) sites. The forests are relatively well preserved, mainly due to the mountainous character of the terrain and poor accessibility in the past. In only $15 \%$ of forests the share of Norway spruce has considerably increased due to spruce planting in the past (Perko, 2004). The latest forest resource inventory shows deciduous forests cover approximately 39\%, coniferous forests $22 \%$ and mixed forests $39 \%$ of forested area. The most abundant tree species in growing stock are Norway spruce (Picea abies Karst. (L.), 35\%), beech (Fagus sylvatica L., 29\%), silver fir (Abies alba Mill., 11\%), oaks (Quercus spp., 8\%) and pines (Pinus spp., 7\%) (Beguš, 1999). Mean growing stock volume was assessed at $282 \mathrm{~m}^{3} /$ ha (Hočevar, 2003). The Act on Forests (1993) prescribes how to maintain productiveness and biodiversity of forests. Forest management goals are based on the principles of sustainability, a multifunctional and cognitive close-to-nature approach. This method of management, among other measures, forbids planting of non-native tree species in the forests. For example, biodiversity is maintained and increased with planned leaving of dead and dying wood biomass, which is the habitat for saprophytic species of invertebrates, fungi and microorganisms (Speight, 1989). Maintenance and increase in forest biodiversity has been strongly affected by Forest Stewardship Council (FSC) certification, which promotes responsible management practice 
and systems that foster adoption of environmentally friendly non-chemical methods of pest management and avoid the use of chemical pesticides. 234,986 hectares of state forest and 25,009 hectares of private forest are certified with the FSC-FM (FM = Forest Management) standard. All of this increases forest's self-regulatory ability to control pests. The result of such management is healthy forest ecosystems which persist, maintain vigour (productivity), organization (biodiversity and predictability) and resilience (time to recovery) (Costanza \& Mageau, 2000). Several studies show that biodiversity is a barrier to ecological invasion (Kennedy, Naeem, Howe, Knops, Tilman, \& Reich, 2002; Leung, Finnoff, Shogren, \& Lodge, 2005; Hudson, Dobson, \& Lafferty, 2006; Csóka, Stone, \& Melika, 2017).

\subsection{Non-Native Insects in Slovenia}

Among invasive non-native species, plant pathogens and phytophages (insects in particular) significantly impact forests, hence the existence of international agreements and legislation to reduce introduction and spread of such organisms (International Plant Protection Convention and similar EU and Slovenian phytosanitary regulations).

Analysis of non-native insect and mite species introduced to Slovenia in the past two centuries shows that over 130 introduced species are harmful to plants. More than $50 \%$ of these species were identified in the past 20 years; Hemiptera, Lepidoptera, Coleoptera, are the most abundant, followed by Diptera, Thysanoptera, Hymenoptera and Acari. 32.8\% of introduced species originate from Asia, 32.1\% from North America, 9\% from Africa, 9\% from South America and Australia, 3.7\% from New Zealand and 13.4\% originate from the Mediterranean or have unknown origin (Seljak, 2013). NEOBIOTA Slovenia 2010-2012 project involved the first systematic analysis based on historical and recent data on non-native organisms in Slovenia, including evaluation of individual non-native species (Jogan, 2012). Our data show that about 212 non-native insects were present in 2016, of which 170 are phytophagous and the rest non-phytophagous (Jurc, 2016). In the past decades insect species such as Dryocosmus kuriphilus Yasumatsu, 1951, Leptoglossus occidentalis Heidemann, 1910, Xylosandrus germanus (Blandford, 1894), Gnathotrichus materiarius (Fitch, 1858), Dasineura gledichiae (Osten Sacken, 1866), Phyllonorycter issikii (Kumata, 1963), Cinara curvipes (Patch, 1912) have been recorded in Slovenian parks and forests (Jurc \& Jurc, 2005; Jurc, Poljaković-Pajnik, \& Jurc, 2009; Jurc \& Jurc, 2010; Jurc, Bojovic, Fernández Fernández, \& Jurc, 2012b; Jurc, 2012). Ophiomyia kwansonis (Jurc, Černý, \& Jurc, 2012a) and some other non-phytophagous and parasitoid species of non-native insects have been found on other plants. Some non-native species are spreading in Slovenian urban forests and affect economic, ecological and other forest functions (Repe \& Jurc, 2009; Jurc, Bojovic, Fernández Fernández, \& Jurc, 2012b).

Invasive insects can displace native species, but it is often unclear whether the 
principal mechanism is predation or competition. A good example is the harlequin ladybird Harmonia axyridis (Pallas, 1773) (Homoptera: Coccinelidae), which is displacing native ladybugs and other native insects in ecosystems in North America and Europe (Majerus, Strawson, \& Roy, 2006; Koch, 2003). The displacement mechanism is not completely understood, it is probably a combination of direct predation of the eggs of native ladybirds and competition by non-native larvae for food.

Of particular interest are species of the Hymenoptera order, which includes important harmful phytophagous species and their parasites or parasitoids such as Neodryinus typhlocybae (Ashmead, 1893) (Hymenoptera: Dryinidae), a parasites of the non-native Metcalfa pruinosa (Say, 1830), or Diptera Trichopoda pennipes (Fabricius, 1781) (Tachinidae), the natural enemy of Nezara viridula (Linnaeus, 1758) (De Groot, Virant-Doberlet, \& Žunič, 2007).

\subsection{Experience with Dryocosmus kuriphilus and Its Parasitoid Torymus sinensis in Slovenia}

The experience with oriental chestnut gall wasp Dryocosmus kuriphilus Yasumatsu, 1951 (Hymenoptera: Cynipidae), which causes damage on Castanea spp. in Asia, the eastern United States and, more recently, in Europe, is instructive. The first outbreak in Europe occurred at a Castanea sativa Mill. nursery in $\mathrm{Cu}$ neo, Italy in 2002. In January 2004, it appeared in Slovenia and, despite destruction of the infested Castanea trees, the pest was not eradicated in outbreak areas and in 2012 it was present in C. sativa stands in all Slovenia. The parasitoid wasp T. sinensis has been used as biocontrol for D. kuriphilus in Japan, North America and in Europe. T. sinensis was introduced in Slovenia at six locations in spring 2015 to 2017. Additional releases are planned in the next four years (Kos \& Melika, 2015; UVHVVR, 2015).

\section{Materials and Methods}

\subsection{Collection of Data in Sources of Data on Non-Native Insects in Slovenia}

Data on non-native insect species were collected with overview of literature data in scientific publications (Google Scholar, ResearchGate, ALARM:

http://www.alarmproject.net/, NOBANIS: http://www.nobanis.org/, DAISIE: http://www.europe-aliens.org/, NAL Catalog (AGRICOLA), EPPO Global Database, COBISS.si and others. We also used results of projects in which we participated (NEOBIOTA Slovenia 2010-2012; Non-native invasive harmful species of fungi and insects affecting forests and forestry 2007-2009 (Jurc, 2009), Development of new detection methods 2014-2017 (Jurc, 2017) and results of research conducted with program funding (P4-0059 Forest, forestry and renewable forest resources, 1999-2019 and P4-0107 Forest biology, ecology and technology 1999-2019). 


\subsection{Survey of $T$. sinensis in Slovenia}

Since 2008, we have studied domestic parasitoid fauna of D. kuriphilus. We determined that the non-native parasitoids of $T$. sinensis in $D$. kuripulius have been present in C. sativa forests since 2012 and attempt to explain this phenomenon.

We analysed the infestation of $D$. kuriphilus with the non-native parasitoid wasp T. sinensis. Galls created in current year and galls from previous year were collected with scisors from C. sativa multiple times in 2013 and 2014 at three locations (Lipa, Rožnik, Velike Brusnice). After harvesting, galls were placed into entomological boxes and kept at room temperature until October 2015, when hatched specimens were stored in $80 \%$ ethanol. Identification of parasitoid $T$. sinensis was conducted in 2016 with morphological analysis (Kamijo, 1982) and comparison of nucleotide sequences of COI and ITS2 regions for specimens sampled in 2013 (Matošević, Lacković, Melika, Kos, Franić, Kriston et al., 2015; Yara, 2004; Yara, 2006).

\subsection{Statistical Analysis}

We used Correspondence Analysis (CA) to describe the relationships between two nominal variables in a correspondence table in a low-dimensional space. Correspondence Analysis (CA) was carried out with the software Statgraphics Centaurion XVI (Statistical Graphics Corporation, U.S.A.).

\section{Results and Discussion}

\subsection{Diversity of Non-Native Insects in Slovenia}

Up to 254 non-native insect species are present in Slovenia, of which around 211 spp. or $83 \%$ are phytophagous (109 spp. or 43\% feed on woody plants, 102 spp. or $40 \%$ on other plants such as crops, vines, grasses, ferns, ornamental flowering plants or seeds), around 30 spp. or $12 \%$ and non-phytophagous (appear on stored food products, fungi, dead wood, guano, saprophags...), 13 spp. or $5 \%$ are parasitoids or predators of other insects or mammals.

Hemiptera includes 17 families (most of which belong to Adelgidae and Diaspididae) with 97 spp., Coleoptera 24 families (Chrysomelidae, Nitidulidae) with 75 spp., Lepidoptera 15 families (Gracillariidae) with 37 spp., Diptera 7 families (Cecidomyiidae, Agromyzidae) with 23 spp., Hymenoptera 8 families (Aphelinidae, Cynipidae) with 13 spp., Thysanoptera 1 family with 9 spp..

Among the phytophagous species, Hemiptera (with 38.2\%) predominate, followed by Coleoptera (29.8\%), Lepidoptera (14.5\%), Diptera (9.0\%), Hymenoptera (5.1\%) and Thysanoptera (3.5\%).

Most of phytophagous species are associated with introduction of plants on which they are specialists, but some have also shifted from introduced to native plant hosts (Csóka, Stone, \& Melika, 2017). 36 non-native phytophagous species or $14.17 \%$ of all non-native insects have become harmful plant pests, including Frankliniella occidentalis (Pergande, 1895); Scaphoideus titanus Ball, 1932; Acizzia jamatonica Kuwayama, 1908; Bemisia tabaci (Gennadius, 1889); Trialeurodes 
vaporariorum (Westwood, 1856); Ceroplastes japonicus Green, 1921; Neopulvinaria innumerabilis (Rathvon, 1854); Saissetia oleae (Olivier, 1791); Diaspidiotus perniciosus Comstock, 1881; Pseudaulacaspis pentagona (Targioni Tozzetti, 1886); Aphis gossypii Glover, 1877; Eriosoma lanigerum (Hausmann, 1802); Macrosiphum euphorbiae (Thomas, 1878); Myzus persicae (Sulzer); Myzus varians Davidson; Viteus vitifoliae (Fitch, 1855); Corythucha ciliata Say, 1832; Corythucha arcuata (Say, 1832); Nezara viridula (Linnaeus, 1758); Acanthoscelides obtectus Say, 1831; Diabrotica virgifera virgifera LeConte, 1858; Leptinotarsa decemlineata Say, 1824; Cacyreus marshalli Butler, 1898; Cameraria ohridella Deschke \& Dimić, 1986; Cydalima perspectalis (Walker, 1859); Grapholita molesta (Busk, 1916); Helicoverpa armigera (Hübner, 1808); Paysandisia archon (Burmeister, 1880); Tuta absoluta (Meyrick J, 1917); Ceratitis capitata (Wiedemann, 1824); Drosophila suzukii (Matsumura, 1931); Liriomyza huidobrensis (Blanchard, 1926); Liriomyza trifolii (Burgess, 1880); Phytomyza gymnostoma Loew, 1858; Rhagoletis cingulata (Loew, 1862); Rhagoletis completa Cresson, 1929; Dryocosmus kuriphilus Yasumatsu, 1951. 20 of them appear on woody plants, but only one of them is in forest-D. kuriphilus.

We used Correspondence Analysis (CA) to describe the relationships between two nominal variables in a correspondence table in a low-dimensional space (Figure 1).

36 non-native phytophagous species (14.17\% of all non-native insects) have become harmful plant pests of crops and urban trees. 20 appear on woody plants, but only one, D. kuriphilus, appears in forest. The number of harmful phytophagous insects in Slovenian forests is extremely small most likely due to high diversity of the forest ecosystem, where close-to-nature, sustainable and multifunctional forest management is practiced. This method of management, among other measures, also does not include planting non-native tree species in the forests and non-chemical methods of pest management. All of this retains forest's self-regulatory ability to control pests.

Non-native non-phytophagous insects that feed on fungi, dead wood, guano, plant products or seeds etc. include Coleoptera (80\%), Lepidoptera (6.5\%), Hymenoptera (6.5\%) and Diptera (6.5\%).

Comparison of inventory of non-native insects in 2012 and 2017 shows the number of non-phytophagous non-native insects is increasing: 173 species were detected in 2012 (around 63\% of species feed on woody plants, 27\% feed on other plants and around 10\% were non-phytophagous) and 254 species in 2017 (around $43 \%$ of species feed on woody plants, around $40 \%$ feed on other plants and around $17 \%$ are non-phytophagous). The ratio is primarily the result of systematic analysis of materials on non-native species, in particular of Coleoptera species in collections of the Natural History Museum in Ljubljana (Vrezec, Kapla, \& Jurc, 2012), systematic work on groups of sucking insects (Seljak, 2013; Jurc, 2016), and scientific studies (V4-1439 Development of new methods of detection, diagnostics and prognosis for non-native organisms harmful to forest 
Correspondence Map

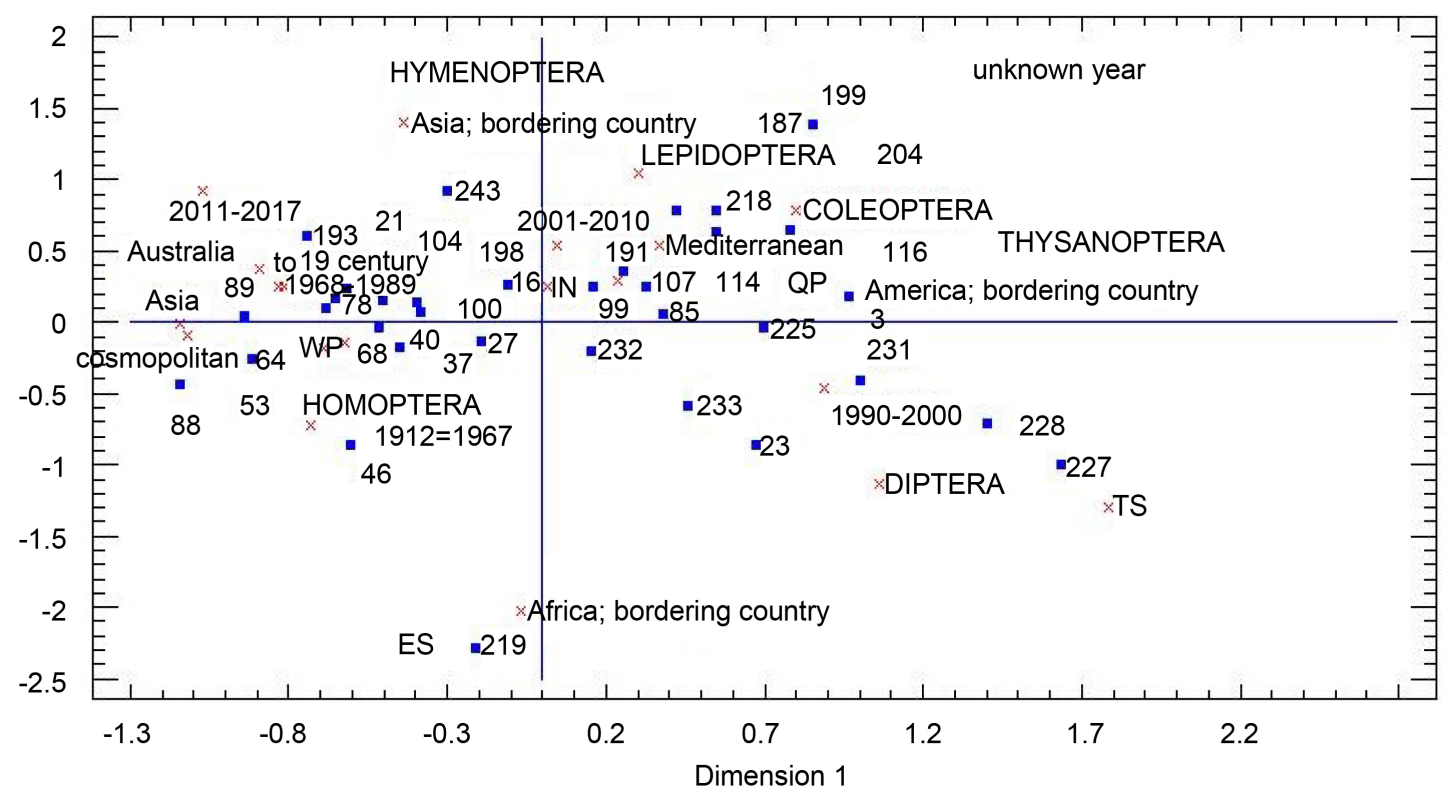

Figure 1. Correspondence Analysis. The distance between any two rows (plant species) and (or) between any two columns (ordo, host plants, origin, years, status) is indicative of their similarity. 36 non-native phytophagous species-harmful plant pests of our crops and urban trees. Legend: (3) Frankliniella occidentalis, (16) Scaphoideus titanus, (21) Acizzia jamatonica, (23) Bemisia tabaci, (27) Trialeurodes vaporariorum, (37) Ceroplastes japonicus, (40) Neopulvinaria innumerabilis, (46) Saissetia oleae, (53) Diaspidiotus perniciosus, (64) Pseudaulacaspis pentagona, (68) Aphis gossypii, (78) Eriosoma lanigerum, (85) Macrosiphum euphorbiae, (88) Myzus persicae, (89) Myzus varians, (99) Viteus vitifoliae, (100) Corythucha ciliata, (104) Nezara viridula, (107) Acanthoscelides obtectus, (114) Diabrotica virgifera virgifera, (116) Leptinotarsa decemlineata, (187) Cacyreus marshalli, (191) Cameraria ohridella, (193) Cydalima perspectalis, (198) Grapholita molesta, (199) Helicoverpa armigera, (204) Paysandisia archon, (218) Tuta absoluta, (219) Ceratitis capitata, (225) Drosophila suzukii, (227) Liriomyza huidobrensis, (228) Liriomyza trifolii, (231) Phytomyza gymnostoma, (232) Rhagoletis cingulata, (233) Rhagoletis completa, (243) Dryocosmus kuriphilus.

2014-2017). In the years 2016 and 2017 in Slovenia we find two new phytophagous insects: Halyomorpha halys (Stål, 1855) (Heteroptera: Pentatomidae) and Corythucha arcuata (Say, 1832) (Heteroptera: Tingidae) were found (Jurc \& Jurc, 2017, in press).

The number of detected non-native parasitoids from the Hymenoptera order and flies has increased as well (Figure 1). Non-phytophagous Hymenoptera species are particularly important and represent $6.5 \%$ of all non-native species. The group includes parasitoids of non-native and native insect fauna (Neodryinus typhlocybae (Ashmead, 1893) Dryinidae; Adelencyrtus aulacaspidis (Brethes, 1914) Encyrtidae; Aphelinus mali (Haldeman, 1851) Aphelinidae; Aphytis mytilaspidis (Le Baron, 1870) Aphelinidae; Encarsia berlesei (Howard, 1906) Aphelinidae; Isodontia mexicana (Saussure, 1867) Sphecidae, and the parasitoid of D. kuriphilus - Torymus sinensis Kamijo, 1982 (Hymenoptera: Torymidae).

\subsection{The Enigma of the Appearances and Spread of T. sinensis}

The chestnut gallwasp, D. kuriphilus, is considered as one of the most serious 
pest damaging chestnut trees (Castanea spp.). After its first detection in Europe, in Italy in 2002, due to the importation of nursery material from China, it is now widely established in the peninsula both in chestnut orchards and forests, and still spreading throughout Europe. It induces the formation of greenish red galls on new shoots and leaves, reducing shoot elongation and fruit production. The pest was controlled in Japan by introducing the parasitoid $T$. sinensis from China's mainland. Following this experience, a classical biological program was started and the parasitoid was introduced into Italy from Japan. Since 2005 individuals of $T$. sinensis were released in several sites covering most of the infested areas. T. sinensis is yet established in Italy and has been also introduced in France, Croatia and Hungary. In Slovenia, T. sinensis was released into nature in April 2015.

D. kuriphilus was introduced to Slovenia in 2004 with sweet chestnut (Castaneasativa Mill.) saplings from Cuneo province in Piedmont, Italy, which were planted in a plantation on Mt. Sabotin. In spring 2007 the insect was detected in the plantation in the $3 \mathrm{~km}$ area around the primary focus Mt. Sabotin. In late June 2007 a considerable proportion of wasps had already hatched, the total demarcated area in 2007 was about $20-30 \mathrm{~km}^{2}$ of woodland. Eradication was unsuccessful and the species started to rapidly spread (Knapič, Seljak, \& Kolšek, 2010). Our data show D. kuriphilus was found in Lipa (near Sežana, the western-most location) in 2008, on Rožnik (Ljubljana, central Slovenia) in 2010 and in Velike Brusnice (near Brežice, the eastern-most location) in 2012. T. sinensis was present at these locations five, three and one year, respectively, after identification of $D$. kuriphilus, indicating that the parasitoid's spread is much faster than the spread of $D$. kuriphilus. Adult T. sinensis was first found on galls collected at Lipa location in May 2013, at Rožnik location in October 2013 and at Velike Brusnice location in September 2013. Comparison was conducted with sequences from GenBank collection using BLAST algorithm (conducted on March 23, 2016). At all three sampling locations T. sinensis was also identified in 2014. All samples contained 4686 galls and 319 T. sinensis specimens hatched (6.8\% of galls were parasitized) (Jurc, Mihajlović, Piškur, \& Jurc, 2016). Of the three locations Lipa is located closest to the area in Italy where the parasitoid was introduced in great numbers in 2005 (Quacchia, Moriya, Bosio, Scapin, \& Alma, 2008). The population of $T$. sinensis at the location was already very large in the June 2013 sample, in which $18.5 \%$ of galls were parasitized. In autumn 2013 T. sinensis was identified in galls samples from all three locations, meaning the parasitoid appeared $125 \mathrm{~km}$ from Lipa. In our study, we kept galls from about a year (sampling in October 2014) to two and a half years (sampling in May 2013). In galls occurred in the current year T. sinensis larvae had sufficient time to fully develop and in some samples, we probably also obtained specimens with extended diapause, as reported by Ferracini, Gonella, Ferrari, Saladini, Picciau, Tota et al. (2015).

Obviously, the T. sinensis population achieved exponential expansion speed 
in Europe unexpectedly fast. The exponential expansion speed happened in Japan seven years after its introduction (Moriya, Bosio, Scapin, \& Alma, 2008). As determined by Colombari \& Battisti (2016), in northern Italy such speed was probably achieved in a year or two (aided by wind): they determined maximum expansion distance of $84.1 \mathrm{~km}$ one year after introduction in one example and $110.5 \mathrm{~km}$ in another example. The results are supported by observations during gall collection in early-March 2016 in Slovenia, when large numbers of galls from previous years were observed at locations around whole Slovenia (Ponikve, Lipa, Puče, Semič, VelikeBrusnice, Majšperk, Grad, Kamnica, Homec, Smoldno, Rožnik) whereas last year's galls were rare and after four days of growing at room temperature $T$. sinensis appeared in abundant numbers. We assume $T$. sinensis significantly reduced the $D$. kuriphilus population in the entire territory of Slovenia.

T. sinensis was released in Slovenia at six locations in spring 2015, 2016 and 2017. Further releases are planned over the next years (Kos \& Melika, 2015; UVHVVR, 2015). Our results suggest that release had probably not been justified and is not sensible in the future since $T$. sinensis had spread on the research area in 2013 and 2014; we believe that its strong potential to reduce the population of $D$. kuriphilus across the entire territory of Slovenia was already well expressed in 2016.

\section{Conclusion}

Introduction of non-native species has been accelerating. The causes are well known: accelerated globalisation of trade in wood and plant products, liberalisation of the Slovenian market since EU accession, and Slovenia being an ecotonic region.

In future increased introduction of non-native insect species is expected; the animals will find favourable living conditions due to climate change, which will reduce competitiveness of native species.

The example of the complex introduction and expansion of D. kuriphilus parasitoid $T$. sinensis merits analysis. It illustrates the complexity of natural processes and shows that any interventions, either introduction of non-native parasites or parasitoids for biocontrol of economically harmful target organisms, or use of pesticides, require utmost caution: non-intervention in natural ecosystem processes is sometimes the best choice.

The small number of non-native insect species in Slovenian forests is probably the result of forests' high biodiversity. Local distribution of non-native species depends on abundance of native species: the higher the diversity of native species, the lower the number of non-native species, because higher species diversity improves ecosystem's self-regulation capabilities (Kennedy, Naeem, Howe, Knops, Tilman, \& Reich, 2002).

It is necessary to intensify the study of bioecology of non-native species, the importance of natural enemies in community impacts and biological control to 
create the scientific basis for appropriate action in future.

\section{Acknowledgements}

The research was conducted as part of the project V4-1439 Development of new methods of detection, diagnostics and prognosis for non-native organisms harmful to forest 2014-2017 and programme groups P4-0059 Forest, forestry and renewable forest resources and P4-0107 Forest biology, ecology and technology. We are grateful for the support.

\section{References}

Beguš, J. (1999). National Forest Development Program. Gozdarska založba, Ljubljana: Ministry of Agriculture, Forestry and Food of Republic of Slovenia.

Colombari, F., \& Battisti, A. (2016). Spread of the Introduced Biocontrol Agent Torymus sinensis in North-Eastern Italy: Dispersal through Active Flight or Assisted by Wind? BioControl, 61, 127-139. https://doi.org/10.1007/s10526-015-9712-1

Costanza, R., \& Mageau, M. (2000). What Is a Healthy Ecosystem? Aquatic Ecology, 33, 105-115. https://doi.org/10.1023/A:1009930313242

Csóka, G., Stone, G. N., \& Melika, G. (2017). Non-Native Gall-Inducing Insects on Forest Trees: A Global Review. Biological Invasions, 1-21. https://doi.org/10.1007/s10530-017-1466-5

De Groot, M., Virant-Doberlet, M., \& Žunič, A. (2007) Trichopoda pennipes F. (Diptera, Tachinidae): A New Natural Enemy of Nezara viridula (L.) in Slovenia: Short Communication. Agricultura, 5, 25-26.

Ferracini, C., Gonella, E., Ferrari, E., Saladini, M. A., Picciau, L., Tota, F., Pontini, M., \& Alma, A. (2015). Novel Insight in the Life Cycle of Torymus sinensis, Biocontrol Agent of the Chestnut Gall Wasp. BioControl, 60, 169-177.

https://doi.org/10.1007/s10526-014-9633-4

Hočevar, M. (2003). The State and Simulation of Sustainable Development of Forest Resources in Slovenia's Forests. In A. Bončina (Ed.), Regional Forest Management Plans and Developmental Perspectives of Slovenian Forestry: Conference Proceedings (pp. 103-122). Ljubljana, Biotechnical Faculty, Department of Forestry and Renewable Forest Resources.

Hudson, P. J., Dobson, A. P., \& Lafferty, K. D. (2006). Is a Healthy Ecosystem One That Is Rich in Parasites? Trends in Ecology and Evolution, 21, 381-385.

Jogan, J. (2012). Neobiota in Slovenia: Invasive Alien Species in Slovenia and Impact on Conservation of Biodiversity and Sustainable Use of Resources. End Report, $251 \mathrm{pp}$. (Last Checked 3 June 2017). http://www.bioportal.si/neobiota.php

Jurc, D. (2009). L4-9585. Invasive Fungi and Insects Harmful for Forests. 2007-2009.

Jurc, D. (2017). V4-1439. Development of New Detection Methods, Diagnosis and Prognosis for Alien Forest Pests. 2014-2017.

Jurc, D., \& Jurc, M. (2005). The Western Conifer Seed Bug (Leptoglossus occidentalis, Hemiptera: Coreidae) Is Rapidly Expanding throughout Slovenia. Gozdarski vestnik, 63, 59-67.

Jurc, M. (2012). The Lime Leafminer (Phyllonorycter issikii) in Slovenia. Šumarski List, 136, 119-127. http://hrcak.srce.hr/file/120568

Jurc, M. (2016). Diversity and Ecological Impacts of Invasive Forest Insects. In M. Jurc 
(Ed.), Invasive Alien Species in Forests and Their Impact on the Sustainable Use of Forest Resources (pp. 233-241). Lectures Presented at the Conference with International Participation, Biotechnical Faculty, Department for Forestry and Renewable Forest Resources, University of Ljubljana, Slovenia.

Jurc, M., \& Jurc, D. (2010). Dasineura gleditchiae (Osten Sacken, 1866) (Diptera: Cecidomyiidae), Honeylocust Pod Gall Midge: A New Invasive Species in Slovenia. $Z b$. gozd. lesar. 91, 89-92.

Jurc, M., \& Jurc, D. (2017). The First Record of Oak Lace Bug Corythuca arcuata (Say, 1832) (Heteroptera: Tingidae). Slovenia. Šum. List. (In Press)

Jurc, M., Bojovic, S., Fernández, M., \& Jurc, D. (2012b). The Attraction of Cerambycids and Other Xylophagous Beetles, Potential Vectors of Bursaphelenchus xylophilus, to Semio-Chemicals in Slovenia. Phytoparasitica, 40, 337-349.

https://doi.org/10.1007/s12600-012-0234-4

Jurc, M., Černý, M., \& Jurc, D. (2012a). First Record of Alien Pest Ophiomyia kwansonis (Diptera: Agromyzidae) in Europe and Its Phytosanitary Significance. Šumarski List, 136, 501-507. http://www.sumari.hr/sumlist/pdf/201205010.pdf

Jurc, M., Mihajlović, L., Piškur, B., \& Jurc, D. (2016). Preliminary Report on the Finding of Parasitoid Torymus sinensis on the Chestnut Gall Wasp (Dryocosmus kuriphilus) in Slovenia in 2013. Novice Izvarstva Gozdov, 9, 8-10.

http://www.zdravgozd.si/nvg/prispevek.aspx?idzapis=9-3

Jurc, M., Poljaković-Pajnik, L., \& Jurc, D. (2009). The First Record of Cinara curvipes (Patch, 1912) (Homoptera, Aphididae) in Slovenia and Its Possible Economic Impact. Zb. gozd. lesar. 88, 21-29.

Kamijo, K. (1982). Two New Species of Torymus (Hymenoptera, Torymidae) Reared from Dryocosmus kuriphilus (Hymenoptera, Cynipidae) in China and Korea. Kontyû, 50, 505-510.

Kennedy, T. A., Naeem, S., Howe, K. M., Knops, J. M. H., Tilman, D., \& Reich, P. (2002). Biodiversity as a Barrier to Ecological Invasion. Nature, 417, 636-638. https://doi.org/10.1038/nature00776

Knapič, V., Seljak, G., \& Kolšek, M. (2010). Experience with Dryocosmus kuriphilus Yasumatsu Eradication Measures in Slovenia. EPPO Bull/Bull OEPP, 40, 169-175. https://doi.org/10.1111/j.1365-2338.2010.02371.x

Koch, R. (2003). The Multicolored Asian Lady Beetle, Harmonia axyridis. A Review of Its Biology, Uses in Biological Control, and Non-Target Impacts. Journal of Insect Science, 32, 1-16. https://doi.org/10.1673/031.003.3201

Kos, K., \& Melika, G. (2015). Chestnut Gall Wasp-The Management Options in Slovenia (pp. 248-256). Lectures and Papers Presented at the 12th Slovenian Conference on Plant Protection with International Participation, Ptuj, 3-4 March 2015, Ljubljana, Plant Protection Society of Slovenia.

Leung, B., Finnoff, D., Shogren, J. F., \& Lodge, D. (2005). Managing Invasive Species: Rules of Thumb for Rapid Assessment. Ecological Economics, 55, 24-36.

Majerus, M., Strawson, V., \& Roy, Y. H. (2006). The Potential Impacts of the Arrival of the Harlequin Ladybird, Harmonia axyridis (Palls) (Coleoptera: Coccinellidae), in Britain. Ecological Entomology, 31, 207-215. https://doi.org/10.1111/j.1365-2311.2006.00734.x

Matošević, D., Lacković, N., Melika, G., Kos, K., Franić, I., Kriston, E., Bozso, M., Seljak, G., \& Rot, M. (2015). Biological Control of Invasive Dryocosmus kuriphilus with Introduced Parasitoid Torymus sinensis in Croatia, Slovenia and Hungary. Periodicum 
Biologorum, 117, 471-477. https://doi.org/10.18054/pb.2015.117.4.3445

Moriya, S., Bosio, G., Scapin, I., \& Alma, A. (2008). Rearing, Release and Settlement Prospect in Italy of Torymus sinensis, the Biological Control Agent of the Chestnut Gall Wasp Dryocosmus kuriphilus. BioControl, 53, 829-839. https://doi.org/10.1007/s10526-007-9139-4

Perko, F. (2004). Slovenian Forests and Forestry. Association of Slovenian Forest Societies. Ministry of Agriculture, Forestry and Food of Republic of Slovenia, Slovenian Forest Service. Ljubljana.

Quacchia, A., Moriya, S., Bosio, G., Scapin, I., \& Alma, A. (2008). Rearing, Release and Settlement Prospect in Italy of Torymus sinensis, the Biological Control Agent of the Chestnut Gall Wasp Dryocosmus kuriphilus. BioControl, 53, 829-839.

https://doi.org/10.1007/s10526-007-9139-4

Repe, A., \& Jurc, M. (2009). New Immigrant Phytophagous Insects on Woody Plants in Slovenia. Presented at 3rd Meeting of Forest Protection Experts and Forest Phytosanitary Experts, 14-16 October 2009, Vienna.

Seljak, G. (2013). The Dynamics of Introduction of the Alien Phytophagous Insects and Mites into Slovenia. Acta Entomologica Slovenica, 21, 85-122.

Speight, M. C. D. (1989). Saproxylic Invertebrates and Their Conservation. Strasbourg: Council of Europe.

UVHVVR (2015). News Release of Parasitoid Wasp for the Suppression of Chestnut Gall Wasp.

http://www.uvhvvr.gov.si/nc/si/medijsko_sredisce/novica/article/1328/5809/

Vrezec, A., Kapla, A., \& Jurc, M. (2012). First List of Alien Beetle Species of Slovenia (Coleoptera). Acta Entomologica Slovenica, 20, 157-178.

Yara, K. (2004). Relationship between the Introduced and Indigenous Parasitoids Torymus sinensis and T. benefices (Hymenoptera: Torymidae) as Inferred from mt-DNA (COI) Sequences. Applied Entomology and Zoology, 39, 27-433. https://doi.org/10.1303/aez.2004.427

Yara, K. (2006). Identification of Torymus sinensis and T. beneficus (Hymenoptera: Torymidae), Introduced and Indigenous Parasitoids of the Chestnut Gall Wasp Dryocosmus kuriphilus (Hymenoptera: Cynipidae), using the Ribosomal ITS2 Region. Biological Control, 36, 15-21. 